\title{
Effects of prematurity and intrauterine growth on respiratory health and lung function in childhood
}

\author{
R J Rona, M C Gulliford, S Chinn
}

\begin{abstract}
Objective-To determine whether birth weight and gestational age are associated with respiratory illness and lung function in children aged 5-11 years.

Design-Cross sectional analysis of parent reported birth weight, gestational age, and respiratory symptoms; parental smoking and social conditions; forced vital capacity (FVC), forced expiratory volume in one second $\left(\mathrm{FEV}_{1}\right)$, forced expiratory rates between $25 \%$ and $75 \%$ and $75 \%$ and $85 \%$ $\left(\right.$ FEF $_{25-75}$ and FEF $\left._{75-85}\right)$, and height.
\end{abstract}

Setting-Primary schools in England and Scotland in 1990.

Subjects-5573 children aged 5-11 $(63 \cdot 3 \%$ of eligible children) had respiratory symptoms analysed and 2036 children $(67 \cdot 1 \%$ of eligible children) had lung function measured.

Main outcome measures-Symptoms of asthma, bronchitis, occasional and frequent wheeze, cough first thing in the morning, and cough at any other time and lung function.

Results-Birth weight adjusted for gestational age was significantly associated with all lung function measurements, except FEF $_{25-75}$. The association remained for FVC $(b=0.475,95 \%$ confidence interval $0 \cdot 181$ to $0 \cdot 769)$ and $\mathrm{FEV}_{1}(b=0.502,0.204$ to 0.800$)$ after adjustment for gestational age, parental smoking, and social factors. FEF $_{75-85}$ was the only lung function related to gestational age. Respiratory symptoms, especially wheeze most days (adjusted odds ratio $0.9,0.84$ to 0.97 ) were significantly associated with prematurity. Every extra week of gestation reduced the risk of severe wheeze by about $10 \%$.

Conclusions-Lung function is affected mainly by intrauterine environment while respiratory illness, especially wheezing, in childhood is related to prematurity.

Department of Public Health Medicine, United Medical and Dental Schools of Guy's and St Thomas's Hospitals, St Thomas's Campus, London SE1 7EH

$\mathrm{R} J$ Rona, reader in public health medicine

M C Gulliford, senior lecturer in public health medicine $\mathrm{S}$ Chinn, reader in medical statistics

Correspondence to: Dr Rona.

$B M F 1993 ; 306: 817-20$

\section{Introduction}

The possibility that intrauterine growth of the fetus might be related to health in childhood and adult life has recently attracted considerable attention. ${ }^{1}$ Birth weight has been used as a measure of fetal growth but it is strongly dependent on gestational age. ${ }^{2}$ Prematurity itself might influence subsequent health and so the effects of prematurity and birth weight (adjusted for gestational age) need to be clearly separated. Low birth weight has been reported to be associated with reduced lung function or with respiratory illness in children, ${ }^{34}$ adolescents, ${ }^{5}$ and adults. ${ }^{6}$ Children whose birth weight was under $2000 \mathrm{~g}$ were more likely to experience troublesome cough, but not wheeze, than controls ${ }^{3}$ and their measures of lung function were significantly reduced. ${ }^{4}$ In a large sample of adolescents low birth weight was associated with increased prevalence of asthma. ${ }^{5}$ Barker et al reported that low birth weight was associated with lower adult lung function but not with symptoms of wheeze. ${ }^{6}$ These results seem to indicate some consistency in the relation between birth weight and lung function, but there is less consensus concerning the relation between birth weight and respiratory symptoms.

Reduced lung function has been associated with low birth weight regardless of whether the child had respiratory complications at birth. ${ }^{478}$ So far only one report has used information for both birth weight and gestational age as independent variables in the analysis. ${ }^{9}$ If poor nutrition in utero is the main cause of the poor lung function children with low birth weight and normal gestational age would be expected to have lower lung function values than those of the same birth weight who were born prematurely. We evaluated children's lung function and respiratory symptoms in relation to both length of gestation and the birth weight adjusted for gestational age.

\section{Subjects and methods}

The national study of health and growth is an annual survey of children aged 5 to 11 years. Information was obtained from English and Scottish samples selected by stratified random sampling of employment exchange areas with proportionally more children from poorer social groups. ${ }^{10}$ These samples have been found to be very similar socioeconomically to a representative sample. " At each survey children are measured and parents are asked to complete a self administered questionnaire. In 1990, 8799 children mainly aged 5 to 11 years were eligible for the study. This was the sample used for the analysis of birth weight, gestational age, and respiratory symptoms. Lung function measurements were carried out in children aged 6.5 to 11 years in a subsample of study areas, resulting in 3036 eligible children.

Parents reported whether their children had suffered from attacks of asthma or bronchitis during the past 12 months, whether they usually coughed first thing in the morning or at any other time, whether their chest ever sounded wheezy or whistling, and, if so, whether this symptom was present on most days or nights.

Lung function was measured with a spirometer attached to a spirogram and digital printout. Each child had three recorded attempts without a noseclip and with a minimum exhalation of 1.5 seconds. For each child forced expiratory capacity (FVC), forced expiratory volume in one second $\left(\mathrm{FEV}_{1}\right)$, and forced expiratory rates between $25 \%$ and $75 \%$ and $75 \%$ and $85 \%\left(\mathrm{FEF}_{25-75}\right.$ and $\left.\mathrm{FEF}_{75-85}\right)$ were recorded. All data from the best blow, defined as the greatest sum of FVC and $\mathrm{FEV}_{1}$, were analysed. Values for each lung function measurement were expressed in standard deviation scores calculated by the method of Bland et $a .^{2}$ The predicted natural logarithm (1n) of lung 
function was derived from multiple regression analysis of $1 n$ lung function on $1 n$ height and $1 \mathrm{n}$ age. The difference between $1 \mathrm{n}$ lung function and the predicted value was antilogged, and the difference between result and the mean of the distribution of the antilogged residuals calculated and divided by the standard deviation. ${ }^{12}$ Standard deviation scores were used to overcome the problem of increasing mean and variance of lung function measurements in the age range 6.5 to 11 years. If SI units had been used results would have had to have been reported by height, age, and sex separately and the sample size would have been too small for useful analysis. Height was measured on a Holtain stadiometer to the last completed $0 \cdot 1 \mathrm{~cm}$ as described by Tanner $e t$ al. ${ }^{13}$

Respiratory symptoms were analysed by multiple logistic regression and lung function standard deviation scores by multiple linear regression. The explanatory independent variables in the analyses were birth weight and length of pregnancy as reported by parents in the questionnaire. Birth weight and gestational age were included as continuous variables. Adjustments were made for the continuous variables triceps skinfold (measured as recommended by Tanner and Whitehouse, ${ }^{14}$ expressed as standard deviation scores calculated by the method of $\mathrm{Cole}^{15}$ ) and reported maternal height. The following categorical variables were used: father's unemployment (yes, no, or not known); father's social class (non-manual, skilled manual, semiskilled and unskilled manual, and not known); one parent in the household (no, yes, not known); mother's age at child's birth $(<20,20-23,24-27,28-31$, $>32$, and not known); mother's education (primary education, secondary education, further education, and university education); number of children (one, two, three, four, five or more, and not known); maternal smoking in pregnancy (no, yes, not known); total number cigarettes smoked at home at the time of the survey $(0,1-4,5-14,15-24,25$ or more, and not known); free school meals (free, not free, not taken, not known if free, and not known); overcrowding $(<1.25$ people per room, $\geqslant 1.25$ people per room, not known); maternal and paternal asthma (no, yes, not known); and study areas (27 areas for the respiratory illness analyses and 17 for the lung function analyses). In the analysis of respiratory symptoms age (as a continuous variable) and sex were also included as independent variables. The continuous variable weight for height ${ }^{16}$ expressed as standard deviation score was adjusted for in the analysis of lung function.

Birth weight was analysed in relation to gestational age by the method of Bland et al. ${ }^{2}$ Expected values of birth weight for gestational age were obtained by regressing the natural logarithm of birth weight on gestational age. The ratio of the observed birth weight to the predicted birth weight for gestational age was used as a measure of birth weight for age. Children with missing values for gestational age or birth weight were excluded from the analysis.

\section{Results}

After excluding children for whom data on the continuous variables were missing $5573(63.3 \%)$ were available for analysis of respiratory illness by birth weight and duration of pregnancy. In the lung function

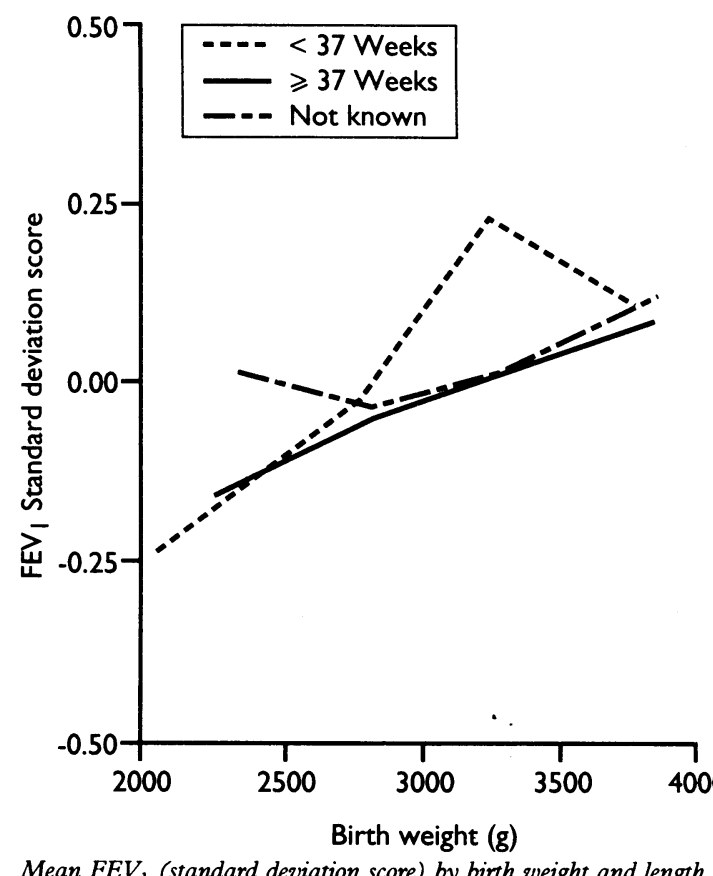
gestation

analysis $2036(67 \cdot 1 \%)$ of 3036 eligible children had useful information on all variables. Valid assessment of lung function was not available for 418 children. For the remaining children excluded from the analysis because of missing data on other variables the mean values for $\mathrm{FEV}_{1}, \mathrm{FVC}, \mathrm{FEF}_{25-75}$, and $\mathrm{FEF}_{75-85}$ were $-0.065,-0.007,-0.08$, and -0.043 standard deviation scores respectively compared with $0.024,0.014$, 0.018 , and 0.004 standard deviation scores for those included. For the 1775 children with information on respiratory illness but not included in that analysis because of other missing data the prevalence of asthma attacks was $7 \cdot 5 \%$, bronchitis $1.8 \%$, cough first thing in the morning $6 \cdot 8 \%$, cough at other times $14.8 \%$, chest ever wheezy $11 \cdot 0 \%$, and wheezy chest most days $3.6 \%$ compared with $5 \cdot 3 \%, 2 \cdot 1 \%, 4 \cdot 2 \%, 11 \cdot 3 \%, 12 \cdot 3 \%$, and $2 \cdot 6 \%$ for those included.

Table I gives the mean values for $\mathrm{FVC}, \mathrm{FEV}_{1}$, $\mathrm{FEF}_{25-75}, \mathrm{FEF}_{75-85}$ according to birth weight and length of pregnancy. For children with normal length of gestation there was a positive association between birth weight and lung function. A similar association was observed for FVC and $\mathrm{FEV}_{1}$ in children with a low gestational age but it was less clear for $\mathrm{FEF}_{75-85}$ and birth weight was unrelated to $\mathrm{FEF}_{25-75}$. Figure 1 illustrates the association between birth weight and $\mathrm{FEV}_{1}$ and the lack of association between duration of pregnancy and $\mathrm{FEV}_{1}$.

Table II shows the regression coefficients for lung function measurements in relation to length of gestation and birth weight adjusted for gestational age. There was a significant positive slope for each lung function measurement with birth weight in the unadjusted model, although the relation with $\mathrm{FEF}_{25-75}$ and $\mathrm{FEF}_{75-85}$ lost significance in the adjusted model. Only $\mathrm{FEF}_{75-85}$ was associated with gestational age $(p<0.05)$. Prevalence of respiratory symptoms was not associated with birth weight, but children with lower gestational age tended to have a greater prevalence of

TABLE I - Lung function measurements expressed in standard deviation score according to mean (SD) birth weight (g) and gestational age (weeks)

\begin{tabular}{|c|c|c|c|c|c|c|c|c|}
\hline & \multicolumn{2}{|c|}{$<2500 \mathrm{~g}$} & \multicolumn{2}{|c|}{$>2500-3000 \mathrm{~g}$} & \multicolumn{2}{|c|}{$>3000-3500 \mathrm{~g}$} & \multicolumn{2}{|c|}{$>3500 \mathrm{~g}$} \\
\hline & $>37(n=55)$ & $\leqslant 37(n=79)$ & $>37(n=274)$ & $\leqslant 37(n=88)$ & $>37(n=716)$ & $\leqslant 37(n=65)$ & $>37(n=725)$ & $\leqslant 37(n=34)$ \\
\hline $\begin{array}{l}\text { FVC } \\
\text { FEV }_{1} \\
\text { FEF }_{25-75} \\
\mathrm{FEF}_{75-85}\end{array}$ & $\begin{array}{l}-0.07(1.45) \\
-0.16(1.38) \\
-0.21(0.99) \\
-0.27(0.80)\end{array}$ & $\begin{array}{l}-0.16(0.77) \\
-0.24(0.76) \\
-0.05(1.22) \\
-0.30(0.94)\end{array}$ & $\begin{array}{l}-0.03(1.17) \\
-0.05(1.19) \\
-0.04(1.09) \\
-0.05(1.03)\end{array}$ & $\begin{array}{r}-0.08(0.94) \\
-0.02(1.12) \\
-0.00(0.96) \\
0.10(1.01)\end{array}$ & $\begin{array}{r}-0.01(0.94) \\
0.01(0.92) \\
0.02(0.94) \\
0.04(0.98)\end{array}$ & $\begin{array}{l}0.14(0.79) \\
0.24(0.87) \\
0.29(1.45) \\
0.11(1.04)\end{array}$ & $\begin{array}{l}0.07(1.00) \\
0.09(1.02) \\
0.05(0.95) \\
0.07(1.06)\end{array}$ & $\begin{array}{r}0.21(0.69) \\
0.11(0.88) \\
-0.15(0.93) \\
-0.06(1.14)\end{array}$ \\
\hline
\end{tabular}




\begin{tabular}{|c|c|c|c|c|c|c|c|c|c|}
\hline & \multicolumn{4}{|c|}{ Birth weight ratiof } & \multicolumn{5}{|c|}{ Length of gestation (weeks) } \\
\hline & \multicolumn{2}{|c|}{ Unadjusted } & \multicolumn{2}{|c|}{ Adjusted } & \multicolumn{3}{|c|}{ Unadjusted } & \multicolumn{2}{|c|}{ Adjusted } \\
\hline $\begin{array}{l}\text { FVC } \\
\text { FEV }_{1} \\
\mathrm{FEF}_{25-75} \\
\mathrm{FEF}_{75-85} \\
\end{array}$ & $\begin{array}{l}0.548 \\
0.624 \\
0.314 \\
0.371 \\
\end{array}$ & $\begin{array}{l}0.834)^{\star \star \star} \\
0.916)^{\star \star \star} \\
0.600)^{\star} \\
0.663)^{\star}\end{array}$ & $\begin{array}{l}0.475(0 \\
0.502(0 \\
0 \cdot 204(- \\
0 \cdot 291(-\end{array}$ & $\begin{array}{l}\text { to } 0 \cdot 769)^{\star \star} \\
\text { to } 0 \cdot 800)^{\star \star} \\
6 \text { to } 0.504 \text { ) } \\
7 \text { to } 0.599)\end{array}$ & & $\begin{array}{l}06(-0.016 \text { to } \\
10(-0.012 \text { to } \\
20(-0.024 \text { to } \\
24(0.002 \text { to } 0 \\
\end{array}$ & $\begin{array}{l}.028) \\
.032) \\
.020) \\
46)^{\star}\end{array}$ & $\begin{array}{r}0.006(-0.01 \\
0.010(-0.01 \\
-0.004(-0.02 \\
0.023(0.001 \\
\end{array}$ & $\begin{array}{l}\text { to } 0.278 \text { ) } \\
\text { to } 0.032 \text { ) } \\
\text { to } 0.018 \text { ) } \\
0.045)^{\star}\end{array}$ \\
\hline \multicolumn{10}{|c|}{${ }^{\star} \mathrm{p}<0.05,{ }^{\star \star} \mathrm{p}<0.01,{ }^{\star \star \star} \mathrm{p}<0.001 .+$ Ratio of observed weight to expected weight for length of gestation. } \\
\hline & & \multicolumn{2}{|c|}{$<2500 \mathrm{~g}$} & \multicolumn{2}{|c|}{$>2500-3000 \mathrm{~g}$} & \multicolumn{2}{|c|}{$>3000-3500 \mathrm{~g}$} & \multicolumn{2}{|c|}{$>3500 \mathrm{~g}$} \\
\hline & & $\begin{array}{c}>37 \\
(n=122)\end{array}$ & $\begin{array}{c}\leqslant 37 \\
(n=220)\end{array}$ & $\begin{array}{c}>37 \\
(n=717)\end{array}$ & $\begin{array}{c}\leqslant 37 \\
(n=226)\end{array}$ & $\begin{array}{c}>37 \\
(n=1957)\end{array}$ & $\begin{array}{c}\leqslant 37 \\
(n=185)\end{array}$ & $\begin{array}{c}>37 \\
(n=2050)\end{array}$ & $\begin{array}{c}\leqslant 37 \\
(n=96)\end{array}$ \\
\hline \multicolumn{2}{|c|}{ Asthma attack } & $7(5 \cdot 7)$ & $11(5 \cdot 0)$ & $52(7 \cdot 3)$ & $12(5 \cdot 3)$ & $95(4 \cdot 9)$ & $8(4 \cdot 3)$ & $102(5 \cdot 0)$ & $10(10 \cdot 4)$ \\
\hline \multicolumn{2}{|c|}{ Bronchitis attacks } & $4(3 \cdot 3)$ & $5(2 \cdot 3)$ & $18(2 \cdot 5)$ & $4(1 \cdot 8)$ & $33(1 \cdot 7)$ & $6(3 \cdot 2)$ & $39(1.9)$ & $6(6 \cdot 3)$ \\
\hline \multicolumn{2}{|c|}{ Cough first thing in morning } & $4(3 \cdot 3)$ & $10(4 \cdot 6)$ & $46(6 \cdot 4)$ & $13(5 \cdot 8)$ & $70(3 \cdot 6)$ & $14(7 \cdot 6)$ & $74(3 \cdot 6)$ & $5(5 \cdot 2)$ \\
\hline \multicolumn{2}{|c|}{ Cough at other times } & $15(12 \cdot 3)$ & $33(15 \cdot 6)$ & $110(15 \cdot 3)$ & $34(15 \cdot 0)$ & $203(10 \cdot 4)$ & $32(17 \cdot 3)$ & $186(9 \cdot 1)$ & $14(14 \cdot 6)$ \\
\hline \multicolumn{2}{|c|}{ Chest ever wheezy } & $12(9 \cdot 8)$ & $33(15 \cdot 0)$ & $97(13 \cdot 5)$ & $32(14 \cdot 2)$ & $222(11 \cdot 3)$ & $27(14 \cdot 6)$ & $243(11.9)$ & $20(20 \cdot 8)$ \\
\hline \multicolumn{2}{|c|}{ Chest wheezy most days } & $2(1 \cdot 6)$ & $10(4 \cdot 6)$ & $31(4 \cdot 3)$ & $9(4 \cdot 0)$ & $37(1.9)$ & $11(6 \cdot 0)$ & $40(2 \cdot 0)$ & $4(4 \cdot 2)$ \\
\hline
\end{tabular}

TABLE IV-Odds ratios (95\% confidence intervals) of respiratory illness according to birth weight ratio and length of pregnancy unadjusted and with adjustment for confounding variables (5573 children)

\begin{tabular}{|c|c|c|c|c|}
\hline & \multicolumn{2}{|c|}{$\begin{array}{l}\text { Odds ratios associated with } 50 \% \text { increase in birth weight } \\
\text { ratio } \dagger\end{array}$} & \multicolumn{2}{|c|}{$\begin{array}{c}\text { Odds ratio associated with one week increase in length } \\
\text { of gestation }\end{array}$} \\
\hline & Unadjusted & Adjusted & Unadjusted & Adjusted \\
\hline Asthma attacks & $0.90(0.61$ to 1.33$)$ & $0.84(0.55$ to 1.28$)$ & $1.02(0.96$ to 1.08$)$ & $1.02(0.96$ to 1.08$)$ \\
\hline Bronchitis attacks & $1.18(0.66$ to 2.14$)$ & & $0.93(0.85$ to 1.01$)$ & \\
\hline Cough first thing in morning & $0.98(0.64$ to 1.49$)$ & $1.03(0.66$ to 1.61$)$ & $0.95(0.89$ to 1.00$)$ & $0.95(0.89$ to 1.01$)$ \\
\hline Cough other times & $0.73(0.55 \text { to } 0.96)^{\star}$ & $0.96(0.72$ to 1.29$)$ & $0.94(0.91 \text { to } 0.98)^{\star \star}$ & $0.95(0.91 \text { to } 0.99)^{\star}$ \\
\hline Chest ever wheezy & $1.12(0.89$ to 1.39$)$ & $1.13(0.85$ to 1.51$)$ & $0.96(0.93$ to 1.00$)$ & $0.96(0.93 \text { to } 1.00)^{\star}$ \\
\hline Chest wheezy most days & $0.64(0.37$ to 1.07$)$ & $0.81(0.46$ to 1.41$)$ & $0.89(0.84 \text { to } 0.95)^{\star \star \star}$ & $0.90(0.84 \text { to } 0.97)^{\star \star}$ \\
\hline
\end{tabular}

${ }^{\star} \mathrm{p}<0.05,{ }^{\star \star} \mathrm{p}<0.01, \star \star \star \mathrm{p}<0.001 .+$ Ratio of observed weight to expected weight for length of gestation.

frequent and occasional wheeze regardless of their birth weight (table III).

Table IV shows the odds ratios for respiratory symptoms in relation to birth weight, expressed as the ratio of observed weight to expected weight for length of gestation, and gestational age before and after adjustment for potential confounding variables. The odds ratios give the association with respiratory illness in relation to the independent variables for a change of one week in length of gestation and $50 \%$ in birthweight ratio. The odds ratios of respiratory illness in relation to birth weight were not significantly different from one-that is, the $95 \%$ confidence interval included one-in the adjusted models and only cough at other times was significantly associated $(p<0.05)$ in the unadjusted analysis. Length of gestation was significantly associated only with wheezy chest most days $(p<0.01)$ and cough at other times $(p<0.05)$ in the adjusted models. Prematurity was not associated with reported asthmatic attacks.

\section{Discussion}

We found that length of gestation but not birth weight was associated with respiratory symptoms, and birth weight but not gestational age was associated with most lung function measurements. The association between length of gestation and respiratory illness was greatest for symptoms of wheeze most days. Every extra week of gestation reduced the risk of wheeze most days in childhood by about $10 \%$. As this was a population study the results on lung function and respiratory illness depended on the majority of children who were term babies and had normal birth weight, with low birth weight or premature infants accounting for only a minority.

Our study has the strengths that the sample sizes were large, the measurements have been carefully standardised, the fieldworkers were trained to measure lung function in a standard manner, and a large number of possible confounding variables were included in the analyses. A possible weakness is that information for both birth weight and length of pregnancy was obtained by parental recall. Accuracy of parental recall of birth weight and length of gestation have been studied by Seidman et al. ${ }^{17}$ They reported that recalled birth weight was accurate to within $100 \mathrm{~g}$ in three quarters of cases and a similar proportion of reported gestational ages were accurate to within one week when compared with hospital records. In their study maternal age, the length of time from birth, and maternal education were not related to the accuracy of reported birth weight.

Tilley et al found that even 10 years after delivery $95 \%$ of mothers were able to classify the birth weight of a child in broad categories. ${ }^{18}$ Moreover researchers have found that internal inconsistencies in hospital case notes are common, especially in children with a low birth weight. ${ }^{17}$ Parents' reports of birth weight and gestational age are sufficiently accurate for analysis and not necessarily worse than hospital case notes; lack of accuracy would decrease rather than increase the strength of the observed associations.

\section{BIRTH WEIGHT AND LUNG FUNCTION}

We wanted to distinguish the possible effects of birth weight and gestational age on lung function and respiratory illness as this approach could provide clues for the differing role of environment in utero and level of maturation. Most of the studies on this topic use only birth weight in the analysis and many of them study small samples of very low birthweight children.

Our results confirm the relation between birth weight and lung function measurements reported in other studies. ${ }^{3-6}$ We calculated the possible effect of birth weight for a given age of gestation on $\mathrm{FEV}_{1}$ using the example of two children of 38 weeks' gestation with the same attributes adjusted for in the analysis but one having a birth weight of $2500 \mathrm{~g}$ and the other $3500 \mathrm{~g}$. If the expected FEV for height and age were 1.51 and the expected birth weight $3300 \mathrm{~g}$ the difference in their expected $\mathrm{FEV}_{1}$ would be $0.026 \mathrm{l}$; this difference would 
increase to 0.0311 for a lower gestational age with an expected birth weight of $2700 \mathrm{~g}$. The same two children with an expected $\mathrm{FEV}_{1}$ for height and age of 2.251 would have an expected difference of 0.0391 in $\mathrm{FEV}_{1}$ if the expected birth weight were $3300 \mathrm{~g}$ and 0.0471 if the expected birth weight were $2700 \mathrm{~g}$. So the approximate possible effect of birth weight on $\mathrm{FEV}_{1}$ would be about $2 \%$ of total $\mathrm{FEV}_{1}$. Gestational age does not contribute to this relation. As we adjusted birth weight for gestational age we can say that environment in utero is an important factor in explaining the association between birth weight and lung function.

The environmental effect on lung function is further supported by the finding in other studies ${ }^{4}$ that among low birthweight children poor forced expiratory function is not dependent on neonatal respiratory events or their treatment. In one of these studies the FVC in low birthweight children was not lower than in a reference group. ${ }^{4}$ In our study most measures of lung function were associated with birth weight. Therefore we could not confirm that airway growth is more vulnerable than peripheral lung growth in low birthweight children as Chan et al showed. ${ }^{4}$ The association was strong and was not explained by confounding variables including parental smoking at home, maternal smoking during pregnancy, and a large number of social factors. In other studies information on maternal smoking during pregnancy was not available. ${ }^{45}$ We found that adjusting for maternal smoking in pregnancy did not change the strength of the association between birth weight and lung function so that the effect of environment in utero on birth weight and subsequently on lung function may be independent of smoking in pregnancy. Differences in the regression coefficients and the $95 \%$ confidence interval between adjusted and unadjusted analyses were minimal in each lung function measurement, underlining the consistency of the findings.

Our analysis did not show any consistent association between the six respiratory symptoms and birth weight, although other researchers have reported associations with various respiratory illnesses. ${ }^{359}$ Alho et al reported that both gestational age and birth weight were independently associated with wheezy bronchitis. ${ }^{9}$ However, Chan et al found an association between birth weight and cough but not wheeze. ${ }^{3}$ Barker et al also failed to find a significant association between birth weight and wheeze. ${ }^{\circ}$ Greenough and colleagues showed that preterm babies who did not require respiratory support had a high prevalence of wheeze and cough in the first year of life. ${ }^{19}$ The respiratory condition in this group of children improved with age. ${ }^{20}$ Furthermore there is no consistency in the reported findings between the type of respiratory illness and birth weight.

\section{GESTATIONAL AGE AND RESPIRATORY SYMPTOMS}

We found a strong association between gestational age and most respiratory symptoms, especially wheezing most days. Most epidemiological studies have not analysed respiratory symptoms in relation to birth weight and gestational age separately. Studies published in the late sixties reported that asthmatic women were more likely to have babies of less than 37 weeks' gestation than non-asthmatic women. ${ }^{21}$ More recently, Bertrand et al suggested a link between familial airway hyperreactivity and premature birth, ${ }^{22}$ but Chan et al were unable to support a role of maternal asthma in low birth weight. ${ }^{23}$ We found no difference in the frequency of low gestational age in asthmatic and non-asthmatic women. In addition maternal and paternal asthma were included in the regression analyses and did not modify the association between independent and dependent variables. Thus a familial component is unlikely to be a confounding variable between gestational age and wheeze in children. This could be because asthma is now better controlled during pregnancy than previously. The relation between respiratory symptoms and length of gestation that we found persisted after adjustment for birth weight and other possible confounding variables. Our analysis suggests that fetal immaturity at birth rather than intrauterine environment would have a role in the aetiology of respiratory symptoms in children.

The mechanisms through which prenatal events influence lung function differ from those that affect respiratory symptoms in children. This explains the consistency of the relation between birth weight and lung function and the lack of it between birth weight and respiratory illness. Immaturity seems to play an important part in the subsequent development of respiratory illness in childhood.

We thank Professor W W Holland for his support, Dr P Burney for his advice, and Ms P Mortley for producing the manuscript. The study was funded by the Department of Health and the Scottish Home and Health Department.

1 Barker DJP, Bull AR, Osmond C, Simmonds SJ. Fetal and placental size and risk of hypertension in adult life. BMF 1990;301:259-62.

2 Bland JM, Peacock JL, Anderson HR, Brook OG, de Curtis M. The adjustment of birthweight for very early gestational ages: two related problems in statistical analysis. Applied Statistics 1990;39:229-39.

3 Chan KN, Elliman A, Bryan E, Silverman M. Respiratory symptoms in children of low birthweight. Arch Dis Child 1989;64:1294-304.

4 Chan KN, Noble-Jamieson CM, Elliman A, Bryan EM, Silverman M. Lung han KN, Noble-Jamieson CM, Elliman A, Bryan EM, Silverman M.
function in children of low birthweight. Arch Dis Child 1989;64:1284-93.

5 Seidman DS, Laor A, Gale R, Stevenson DK, Denon YL. Is low birthweight a risk factor for asthma during adolescence? Arch Dis Child 1991;66:584-7.

6 Barker DJP, Godfrey KM, Fall C, Osmond C, Winter PD, Shaheen SO. Relation of birth weight and childhood respiratory infection to adult lung function and death from chronic obstructive airways disease. BMJ 1992; 303:671-5

7 Galdes-Sebaldt M, Sheller JR, Grogaard J, Stahlman M. Prematurity is associated with abnormal airway function in childhood. Pediatric Pulmonology 1989;7:259-64

8 Mansell AL, Driscoll JM, James LS. Pulmonary follow-up of moderately low birthweight infants with and without respiratory distress syndrome. f Pediatr 1987;110:111-5.

9 Alho O-P, Koivu M, Hartikainen-Sorri, Sorri M, Kikku O, Rautakallio P. Is a child's history of acute otitis media and respiratory infection already determined in the antenatal and prenatal period? Int $f$ Pediatr determined in the antenatal
Otorhinolaryngol 1990;19:129-37.

10 Rona R, Altman DG. National study of health and growth: standard of attained height, weight and triceps skinfold in English children 5 to 11 years old. Ann Hum Biol 1977;4:501-23.

11 Osborn AF, Butler NR, Morris AC. The social life of Britain's five-year olds. A report of child health and education study. London: Routledge and Kegan Paul, 1984

12 Chinn S, Rona RJ. Height and age adjustment for cross sectional studies of pulmonary function in children aged 6 to 11 years. Thorax 1992;47:707-14.

13 Tanner JM, Whitehouse RH, Takaishi M. Standards from birth to maturity for height, weight, height velocity and weight velocity. British children 1965. Arch Dis Child 1966;41:454-571.

14 Tanner JM, Whitehouse RH. Revised standards for triceps and subscapular skinfolds in British children. Arch Dis Child 1975;50:142-5.

15 Cole TJ. Fitting smoothed centile curves to reference data (with discussion). fournal of the Royal Statistical Society of America 1988;151:385-418.
.

16 Chinn S, Rona RJ, Gulliford MC, Hammond J. Weight for height in children aged 4 to 12 years. A new index compared to the normalized body mass
a ndex. Eur F Clin Nutr 1992;46:489-500

17 Seidman DS, Slater PE, Ever-Hadani P, Gale R. Accuracy of mother's recall of birthweight and gestational age. Br F Obstet Gynaecol 1987;94:731-5.

8 Tilley BC, Barnes AB, Bergstralh E, Labarthe D, Noller KL, Colton T, Adam E. Comparison of pregnancy history recall and medical records. $A m \mathcal{F}$ Epidemiol 1985;121:269-81.

19 Greenough A, Maconochie I, Yuksel B. Recurrent respiratory symptoms in the first year of life following preterm delivery. I Perinat Med 1990;18: $489-94$.

20 Greenough A, Milner AD. Comment. Prematurity and asthma-is there a link? Curr Med Literature. Reversible Obstructive Airways Disease 1992;6: 31-5.

21 Greenberger PA, Patterson R. Current concepts. Management of asthma during pregnancy. $N$ Engl f Med 1985;312:897-902.
d

22 Bertrand J-M, Reley P, Popkin J, Coates AL. The long-term pulmonary sequelae of prematurity: the role of familial airway hyperreactivity and the respiratory distress syndrome. $N$ Engl 7 Med 1985;312:742-5.

23 Chan KN, Noble-Jamieson CM, Elliman A, Bryan EM, Aver VR, Silverman $\mathrm{M}$. Airways responsiveness in low birthweight children and their mothers. Arch Dis Child 1988;63:905-10.

(Accepted 25 fanuary 1993) 